Academic Platform Journal of Engineering and Science

\title{
Değişken Manyetik Alan ve Diyamanyetik Malzemeler ile Isı Eldesi
}

\author{
${ }^{1}$ Arda Zaim, *2Agah Aygahoğlu \\ ${ }^{1}$ Kütahya Dumlupınar Üniversitesi, Mühendislik Fakültesi, Makine Mühendisliği Bölümü, arda.zaim@gmail.com, \\ ${ }^{2}$ Kütahya Dumlupınar Üniversitesi, Mühendislik Fakültesi, Makine Mühendisliği Bölümü, agah.aygahoglu@dpu.edu.tr, \\ Araştırma Makalesi \\ Geliş Tarihi: 25.01.2018 \\ Kabul Tarihi: 29.08.2018
}

$\ddot{O} \mathbf{z}$

Bu çalışmada, hareket enerjisiyle değişken manyetik alan oluşturularak verimli bir şekilde 1sı elde etmek amaciyla N35 neodyum mıknatıs ve diyamanyetik bir malzeme olan C1020 bakır alaşımını içeren düzenekle deneysel çalışmalar yapılmıştır. Yapılan deneylerde değişken manyetik alan etkisinde kalan bakıın, manyetizmanın temel kanunları olan Lenz ve Faraday Kanunları ve bunlara bağlı olarak meydana gelen Eddy Akımları sayesinde 1sındığı gözlenmiştir. Devir sayısı ve mıknatıs ile malzeme arasındaki mesafe değiştirilerek, verimli isı enerjisi elde etmek için optimum parametreler belirlenmiştir. Düzenekte $2400 \mathrm{~d} / \mathrm{dk}$ hız ve $2 \mathrm{~mm}$ mıknatısa olan uzaklık parametrelerinde $\% 75,8$ verime ve $54,7^{\circ} \mathrm{C}$ su sıcaklığına ulaşılmışıtır. Sistem verimi de göz önünde bulundurularak, yöntemin alternatif enerji kaynaklı ve ekonomik bir 1sıtma sistemi olarak değerlendirebileceği kanısına varılmıştır.

Anahtar kelimeler: Alternatif Enerji Kaynakları, Bakır Alaşımları, Isı Enerjisi, Manyetik Alan.

\section{Heat Obtain with Variable Magnetic Field and Diamagnetic Materials}

\author{
${ }^{1}$ Arda Zaim, ${ }^{* 2}$ Agah Aygahoglu \\ ${ }^{1}$ Kütahya Dumlupinar University, Engineering Faculty, Mechanical Engineering Department, arda.zaim@gmail.com \\ ${ }^{2}$ Kütahya Dumlupinar University, Engineering Faculty, Mechanical Engineering Department, agah.aygahoglu@dpu.edu.tr
}

\begin{abstract}
In this study, experimental studies were carried out by setting a mechanism that includes N35 neodymium magnet and diamagnetic material such as C1020 copper alloy to obtain heat with variable magnetic field from motion energy efficiently. In the experiments performed, the material exposed to the variable magnetic field were observed to be heated by the Lenz and Faraday Laws, which are the basic laws of magnetism, and the Eddy Currents formed by it's. Optimum parameters have been determined by changing the speed and the distance between the magnet and the material.In the mechanism, a speed of 2400 $\mathrm{rpm}, \% 75,8$ of efficiency in the distance parameter to the $2 \mathrm{~mm}$, and also $54,7^{\circ} \mathrm{C}$ of water temperature are achieved. With taking the system efficiency into consideration, this system can be considered as an alternative energy source and an economical way of heating.
\end{abstract}

Keywords: Alternative Energy Sources, Copper Alloys, Heat Energy, Magnetic Field. 


\section{GÍRIŞ̧}

Artan nüfus ve gelişen teknoloji daha fazla enerji talebini gerektirmekte, bu durum ise enerji temini için yeni teknolojik yöntemlerin gerekliliğini doğurmaktadır. Yeni yöntemlerin asıl amac1; üretim ve işletme maliyetleri düşük, çevre dostu, sosyal değerlere duyarlı ve efektif bir biçimde enerjinin tedarik edilmesidir [1]. Dünya enerji gündemindeki konular şöyle sıralanabilir; enerjinin verimli kullanımı, etkin enerji yönetimi, alternatif yakıt seçenekleri ve uygulanabilirliği, yenilenebilir enerji kaynakları ve enerji kullanımının neden olduğu çevre sorunları.

Fosil yakıt rezervlerinin hılı bir şekilde tükenmesi ve nüfus artışıyla birlikte alternatif enerji kaynaklarının kullanımı yaygınlaşmaktadır [2,3].

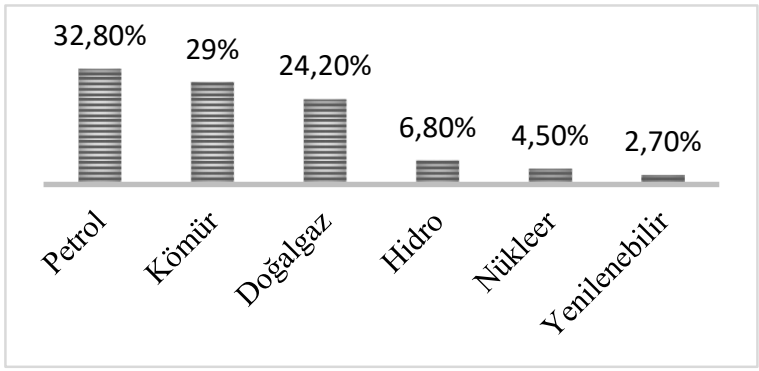

Şekil 1. 2015 Dünya birincil enerji tüketim oranları [3].

Şekil 1.'de görüldüğü gibi günümüzde kullanmakta olduğumuz enerjinin büyük kısmı fosil yakıtlardan sağlanmaktadır. Ancak fosil yakıtların yanmasıyla açığa çıkan $\mathrm{CO}_{2}$ gazı ciddi ve tehlikeli boyutlarda çevre sorunlarına yol açmaktadır. $\mathrm{CO}_{2}$ gazının neden olduğu küresel 1sınmanın önüne geçmek için $\mathrm{CO}_{2}$ emisyon miktarının azaltılması gerekmektedir.

Çevreye zararlı etkisi olan ve rezervleri sınırlı olan fosil yakıtların yerine yakın gelecekte alternatif olarak kullanılabilecek enerji kaynaklarının bulunması bir zorunluluk haline gelecektir [4]. Bu çalışmada sonuç olarak bir sıvıyı ısıtmak amaçlanmıştır ve literatürde bir akışkanı 1sıtmak amaciyla, konvansiyonel enerji kaynaklarına alternatif olarak onlarca çalışma mevcuttur. Örneğin; Chow ve arkadaşları hibrit fotovoltaik - termosifon su 1sıtma sisteminin konutlarda uygulanabilirliği üzerine çalışmıştır $[5]$.

Diğer bir çalışmalarında ise fotovoltaik su 1sıtma sisteminin deneysel performansını belirlemiştir [6]. Hawlader ve arkadaşları güneş enerjisi destekli 1sı pompalı su 1sıtma sisteminin performansını araştırmıştır [7]. Altıntaş ve arkadaşları indüksiyon 1sıtma prensibi ile çalışan mikrokontrol denetimli bir sıvı 1sıtıcısı tasarlamış ve deneysel çalışmalar yapmıştır [8].

Manyetik enerji; kaynağının kısıtlı olmaması, çevreye duyarlı olması ve kullanımının tehlike oluşturmaması gibi özellikleri sebebiyle alternatif enerji kaynakları arasında sınıflandırılmaktadır. Günümüze kadar manyetik enerji üzerine çeşitli çalışmalar yapılmıştır. Yuan ve arkadaşları, DZ483 alaşımına manyetik ısıl işlem uygulayarak alaşımın mikroyapısını ve mekanik özelliklerini incelemiştir [9]. Teyber ve arkadaşları manyetik ısı pompalarının maliyetini düşürmek için yeni bir kalıcı mıknatıs tasarlamıştır [10]. Jacobs ve arkadaşları $2 \mathrm{~kW}$ soğutma gücüne sahip bir döner manyetik soğutucunun farklı akış miktarlarındaki performansını araştırmıştır [11]. Eriksen ve arkadaşları yeni bir döner manyetik soğutucu tasarlamış ve üretilen prototiple deneysel çalışmalar yapmıştır [12]. Bahl ve arkadaşları kesintisiz çalışabilen döner manyetik rejeneratör tasarlamış ve deneysel çalışmalar yapmıştır [13].

Özet olarak sunulan literatür araştırmasından, değişken manyetik alan ve bununla etkileşim altında olan diyamanyetik malzeme ile 1sı elde eden ve bu 1sı1y bir akışkanı 1sıtmak için kullanan sistemin deneysel performans analizlerinin konu edildiği bilimsel anlamda bir araştırma olmadığı görülmektedir. Bu çalışmada değişken manyetik alan ve diyamanyetik malzeme kullanılarak hareket enerjisinden 1s1 enerjisi elde eden ve bu 1s1 enerjisini bir akışkanı ısıtmak için kullanan sistemin çeşitli durumlardaki performans parametreleri karşılaştırmalı olarak sunulmaktadır.

\section{MATERYAL VE METOT}

Değişken manyetik alan kullanılarak 1Sı üretilecek deney düzeneği Şekil 2.'de gösterilmektedir. Düzenek; Şekil 3.'te çizimi gösterilen ters kutuplu (S - N) N35 neodyum mıknatısların dizili olduğu rotor, C1020 alaşımından imal edilmiş 1,3 x 10-2 $\mathrm{m}^{2}$ kesit alanına sahip bakır boru, $16 \mathrm{lt} / \mathrm{dk}$ debiye sahip sirkülasyon pompası ve su tankından oluşmaktadır. Düzenek $1.1 \mathrm{~kW}$ gücündeki trifaz asenkron bir elektrik motoru tarafından tahrik edilmektedir. Elektrik motoru ise Danfoss marka frekans invertörüyle kontrol edilmektedir.

Deneysel çalışmalara başlamadan önce sisteme 2.5 lt hacminde saf su şarj edilmiştir. Sistem sırasıyla 1800, 2100 ve $2400 \mathrm{~d} / \mathrm{dk}$ hızlarda çalıştırılmıştır. Sistem hızı stabil hale geldikten sonra sıcaklık ve enerji tüketim ölçümleri yapılmıştır. $\mathrm{Bu}$ ilk testin ardından rotor ile bakır boru arasındaki uzaklık sırasıyla 2, 4 ve $6 \mathrm{~mm}$ olacak şekilde testlere devam edilmiştir. Oda sıcaklığı koşullarında; sistemin hızı, elektrik motorunun enerji tüketimi, tanktaki suyun testlerden önceki ve sonraki sıcaklıkları, test süreleri kayıl edilmiştir. Sistemin hızı her testten önce invertör aracılığıyla ayarlanmıştır. Sıcaklık ölçümlerinde Loyka marka saplama problu termometre kullanılmıştır. Güç ve akım değerleri invertör üzerinde bulunan voltmetre ve ampermetrelerden okunmuştur. Testlerde kullanılan mıknatısların manyetik alan şiddetlerinin ölçümü WT-10A model teslametre ile yapılmıştır.

Sistemin performansını hesaplayabilmek için aşağıdaki varsayımlar kabul edilmiştir; 
- 12 watt gücündeki sirkülasyon pompasının enerji tüketimi ihmal edilebilir.
- Kayış - kasnak mekanizmasındaki sürtünme kayıpları ihmal edilebilir.

- Elektrik motoru \%100 verimle çalışmaktadır

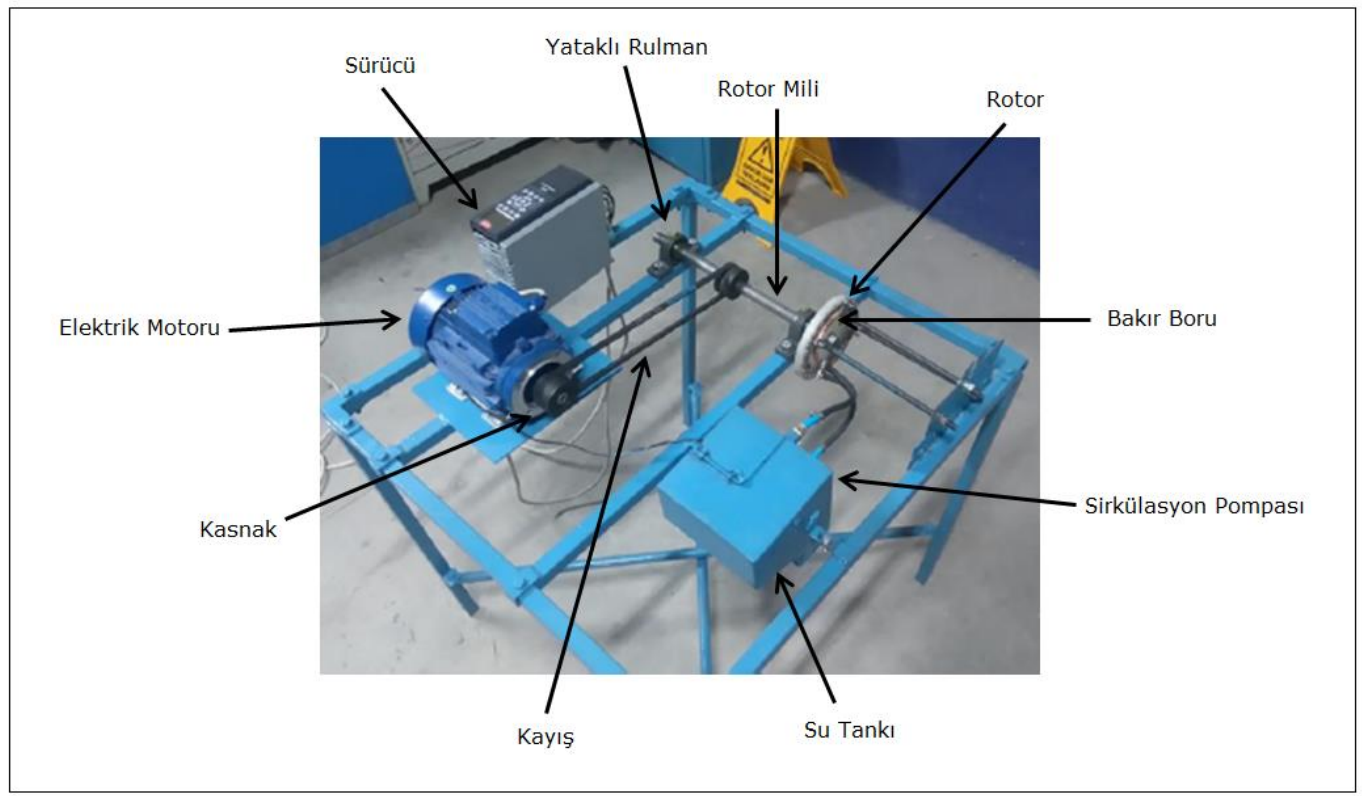

Şekil 2. Deney düzeneği

Sistem performansı ile ilgili parametreler aşağıdaki gibi hesaplanmıştır.

Sistemin tükettiği elektrik enerjisi $\left(Q_{E}\right)$ 1 no'lu eşitlik kullanılarak hesaplanmıştır.

$Q_{E}=\sqrt{3} . \mathrm{U} . \mathrm{I} \cdot \cos \Phi .860 \cdot 0,33$

Burada U; iki faz iletkeni arasında ölçülen etkin gerilimi, I faz iletkeninden ölçülen etkin akımı, $\cos \Phi$; elektrik motorunun güç faktörünü, $860 ; \mathrm{kWh}-\mathrm{kcal}$ dönüşüm katsayısını ve 0,$33 ; 20$ dakika olan deney süresinin saat olarak değerini ifade etmektedir.

Sistemde üretilen 1sı enerjisi $\left(Q_{I}\right) 2$ no'lu eşitlik kullanılarak hesaplanmıştır.

$Q_{I}=\mathrm{m} \cdot \mathrm{c} \cdot \Delta \mathrm{t}$

Eşitlikte m; akışkan kütlesini, c; akışkanın özgül ısısını, $\Delta \mathrm{t}$ ise akışkandaki sıcaklık farkını ifade etmektedir.

Sistemin verimi (n) 3 no'lu eşitlik kullanılarak hesaplanmıştır. $Q_{E}$ sistemin tüketmiş olduğu elektrik enerjisini, $Q_{I}$ ise sistemde üretilen 1 s1 enerjisini belirtmektedir.

$\eta=\frac{Q_{I}}{Q_{E}}$

Tüm ekipmanlar ve ölçümler belirli teknik özelliklere sahiptir. Bu özellikler doğru bir ölçüm yapabilmek için hassas olmalıdır. Hatalar ve belirsizlikler; deney cihazlarının seçiminden çevreye, gözlem ve okumaya kadar değişik etkilerden kaynaklanmaktadır [14].

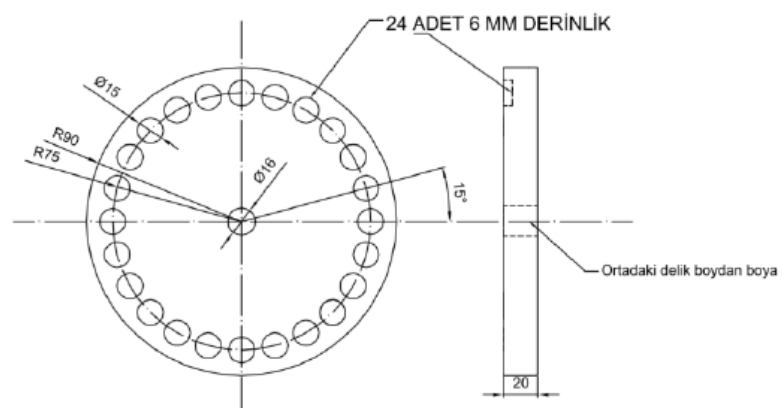

Şekil 3. Mıknatıs dizili rotorun çizimi

Çalışmada kullanılan ölçüm cihazlarının hata oranları Tablo 1.'de gösterilmektedir. Bu deneysel çalışmada kullanılan ölçüm cihazları tarafından tespit edilen değerlerin az da olsa hatalı olduğu unutulmamalıdır.

Tablo 1. Ölçü aletleri hata oranlar

\begin{tabular}{|l|l|}
\hline Ölçü Aleti & Hata Oranı \\
\hline Termometre & $\pm 0.6 \%$ \\
\hline Voltmetre & $\pm 1 \%$ \\
\hline Ampermetre & $\pm 1 \%$ \\
\hline Takometre & $\pm 1.2 \%$ \\
Teslametre & $\pm 0.8 \%$ \\
\hline
\end{tabular}




\section{SONUÇLAR VE TARTIȘMA}

Deneysel verilere dayanılarak çeşitli varyasyonlar için (farklı hızlar ve rotor ile boru arasındaki farklı uzaklıklar) sistemde üretilen 1sının, hız ile değişimi Şekil 4.'te gösterilmektedir. Şekil 4.'teki karakteristik eğrilerden görüldüğü üzere sistemde üretilen $1 s 1$, hız ile orantılı olacak şekilde artmaktadır.

$1800 \mathrm{~d} / \mathrm{dk}$ hızdan $2400 \mathrm{~d} / \mathrm{dk}$ hıza çıkıldı ̆̆ında sistemde üretilen 1sı enerjisi 2, 4 ve $6 \mathrm{~mm}$ parametrelerinde sirasıyla $\% 80,6, \% 107, \% 135$ artış göstermiştir. $2400 \mathrm{~d} / \mathrm{dk}$ hız ve 2 $\mathrm{mm}$ miknatıs ile boru arasındaki mesafe parametrelerinde üretilen 1sı miktarı $84,75 \mathrm{kcal}$ ile maksimumdur.

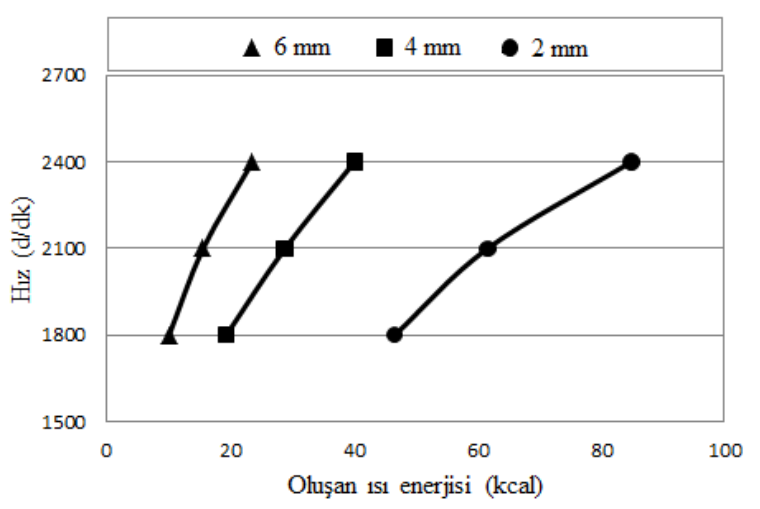

Şekil 4. Hız ile üretilen 1sı enerjisinin değişimi.

Sistemdeki 1sı üretimini etkileyen diğer parametre ise mıknatıs ile boru arasındaki uzaklıktır. Şekil 5.'de sistemde üretilen 1sının, mıknatısa olan uzaklık ile değişimi gösterilmektedir.

Şekil 5.'te gösterilen karakteristik eğrilerde sistemde üretilen 1sının tüm hızlarda artan uzaklık ile azaldığı açıkça görülmektedir. Bu durum boru üzerine etki eden manyetik alan şiddetinin artan uzaklık ile azalmasına bağlanabilir.

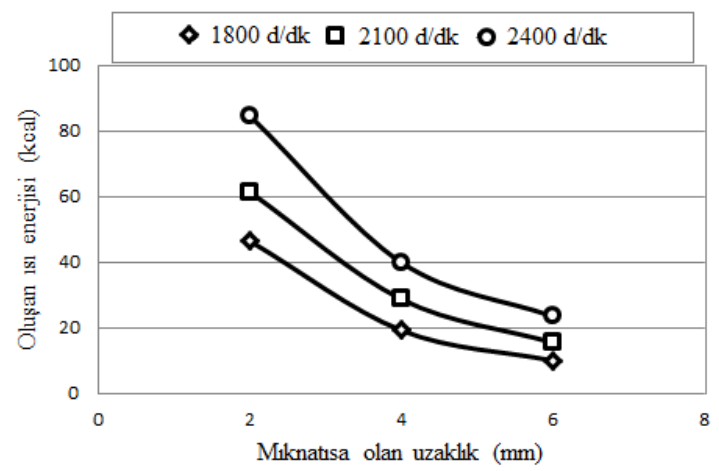

Şekil 5. Miknatısa olan uzaklık ile sistemde üretilen 1S1 enerjisinin değişimi

Şekil 6.'da hız ile sistemde tüketilen elektrik enerjisinin değişimi gösterilmektedir. Tüm durumlar için artan hız ile tüketilen elektrik enerjisi miktarı da artış göstermektedir. $\mathrm{Bu}$ duruma, artan hızla motorun şebekeden çektiği akım artışı neden olmaktadır.

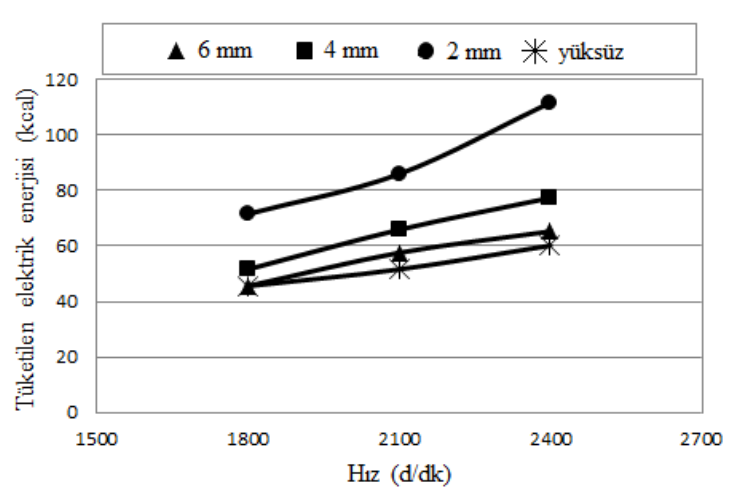

Şekil 6. Hız ile tüketilen elektrik enerjisinin değişimi.

Elektrik motoru yüksüz iken $2400 \mathrm{~d} / \mathrm{dk}$ hizda 60,2 kcal enerji tüketmektedir. Miknatısa olan uzaklığın $2 \mathrm{~mm}$ olduğu durumda ise motorun tükettiği elektrik enerjisi miktarı \%85,7 artış göstererek maksimum değer olan 111,8 kcal'e ulaşmaktadır. Şekil 7.'de hız ile sistem veriminin değişimi gösterilmektedir. Karakteristik eğriler incelendiğinde tüm durumlar için hız artışıyla verim de artmaktadır. $\mathrm{Bu}$ artış, sistemde üretilen $1 \mathrm{~s} 1$ enerjisinin sistemde tüketilen elektrik enerjisine oranla daha fazla olmasıyla açıklanabilir.

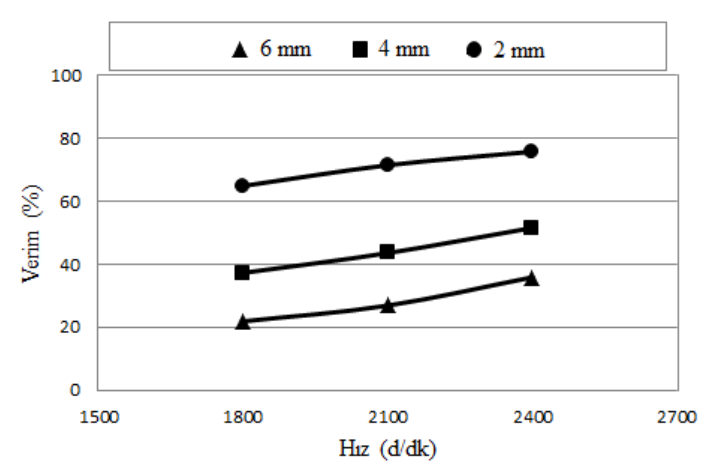

Şekil 7. Hız ile sistem veriminin değişimi.

$1800 \mathrm{~d} / \mathrm{dk}$ hızdan $2400 \mathrm{~d} / \mathrm{dk}$ hıza çıkıldığında sistem verimi 2, 4 ve $6 \mathrm{~mm}$ miknatısa uzaklık parametrelerinde sırasıyla $\%$ 10,9, \% 14,3, \%14 artış göstermiştir. 4 mm uzaklıkta en yüksek oranda verim artışı olurken, en yüksek verim $\% 75,8$ ile $2 \mathrm{~mm}$ miknatisa uzaklık ve $2400 \mathrm{~d} / \mathrm{dk}$ hiz parametrelerinde elde edilmiştir.

Şekil 8.'de hız ile belirlenen test süresi (20 dakika) sonunda ulaşılan su sıcaklığının değişimi gösterilmektedir. Sistemde başlangıç sıcaklığı $20^{\circ} \mathrm{C}$ olan su sıcaklığı $2400 \mathrm{~d} / \mathrm{dk}$ hız ve $2 \mathrm{~mm}$ mıknatısa uzaklık parametrelerinde $54,7^{\circ} \mathrm{C}$ 'dir ve kullanılan deney değişkenlerine göre bu sıcaklık maksimum su sıcaklığıdır. Testler sonunda ulaşılan minimum ve maksimum su sıcaklık değerleri arasında $30,6{ }^{\circ} \mathrm{C}$ fark vardir.

Şekil 8.'deki karakteristik eğriler incelendiğinde hızın 1800 d/dk'dan 2400 d/dk'ya ulaşmasıyla $2 \mathrm{~mm}, 4 \mathrm{~mm}$ ve 6 mm mıknatısa uzaklık parametrelerinde su sıcaklığında sırasıyla \% 38,8, \%31,6, \%21,5 oranında artış meydana geldiği görülmektedir. 


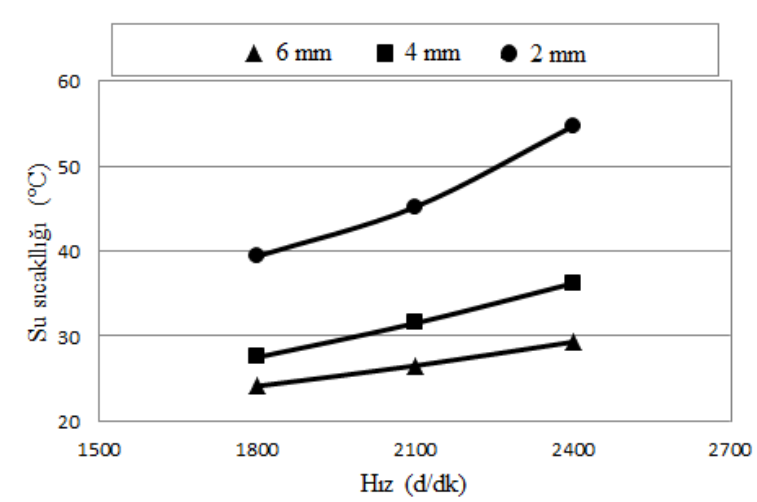

Şekil 8. Hız ile test süresi sonrasında ulaşılan su sıcaklığının değişimi.

Sistemin en verimli olduğu ve maksimum su sıcaklığına ulaşılan varyasyonu olan $2 \mathrm{~mm}$ mıknatısa uzaklık ve 2400 $\mathrm{d} / \mathrm{dk}$ hız parametreleri için spesifik enerji tüketimi 1,28 $\mathrm{kcal} /{ }^{\circ} \mathrm{C}$ olarak hesaplanmıştır. Konvansiyonel rezistanslı bir su 1sıtıcısının spesifik enerji tüketimini belirlemek amacıyla 2000 watt gücündeki isıtıcı ile testler yapılmıştır. Testler sonucunda rezistanslı su isıtıcısının spesifik enerji tüketimi aynı su miktarı için $1,42 \mathrm{kcal} /{ }^{\circ} \mathrm{C}$ olarak tespit edilmiştir. Değişken manyetik alanla 1sı elde ederek su 1sitan sistem, konvansiyonel reziztanslı sisteme göre \%10,9 oranla daha az enerji tüketmektedir.

Testlerden önce rotorda kullanılan 24 adet N35 neodyum mıknatıs arasından rastgele seçilen 5 tanesinin ortalama manyetik alan şiddeti 301,2 mT olarak ölçülmüştür. Testlerden sonra yapılan ölçümlerde ise bu değer 300,2 mT olarak belirlenmiştir. Miknatıs kullanarak değişken manyetik alan oluşturulması ve diyamanyetik bir malzemenin 1sitılması prosesinde kullanilan miknatısların manyetik alan şiddetlerin önemli bir değişim gözlenmemiştir.

\section{SONUÇ}

$\mathrm{Bu}$ çalışmada, hareket enerjisiyle değişken manyetik alan oluşturularak verimli bir şekilde 1sı elde etmek amacıyla N35 neodyum miknatıs ve diyamanyetik bir malzeme olan C1020 bakır alaşımını içeren düzenekle deneysel çalışmalar yapılmıştır. Burada bildirilen pratik çalışmalarda, manyetik enerjiyle su 1sıtmak için tasarlanan düzenekte farklı parametrelerle testler yapılmış olması bu çalışmayı literatürde daha çekici hale getirmektedir. Test sonuçları, sistemde üretilen 1 sının hiz ve miknatısa olan uzaklıkla değiştiğini kanıtlamıştır. Testlerde, belirlenen 20 dakikalık deney süresi içinde ulaşılan maksimum su sicaklığı olan $54,7^{\circ} \mathrm{C}, 2400 \mathrm{~d} / \mathrm{dk}$ hiz ve $2 \mathrm{~mm}$ miknatısa uzaklık parametrelerinde elde edilmiştir. Bu durumda sistem verimi \%75,8 olarak hesaplanmıştır. Sistem, konvansiyonel reziztansl1 su 1sitic1 sistemlerine \%10,9 daha az enerji tüketmektedir. Devir daim suyunun sicaklık değeri prototip sistem için iyi sayılabilecek bir değer olarak yorumlanmıştır. Manyetik alan şiddeti daha büyük ve çok sayıda mıknatıs, devir sayısı yüksek mekanizma ve farklı rotor tipleri ile oluşturulacak sistemlerde daha yüksek su sıcaklık değerlerine ulaşılabilir. Elde edilen sıcak su ile konutların ve seraların ısıtılması sağlanabilir. Bu çalışma için tasarlanıp, prototip olarak üretilen düzenekle oluşturulan 1S1 enerjisi, endüstrinin birçok kolunda kullanılabilir. Sistemin verimi de göz önünde bulundurularak, yöntemin alternatif enerji kaynaklı ve ekonomik bir 1sıtma sistemi olarak değerlendirilebileceği kanısına varılmıştır. Sistem ile ilgili geliştirme çalışmalarına devam edilmektedir.

\section{KAYNAKÇA}

[1] Kubilay Kavak, “Dünya'da ve Türkiye'de Enerji Verimliliği ve Türk Sanayiinde Enerji Verimliliğin İncelenmesi" Uzmanlık Tezi, Devlet Planlama Teşkilatı, Ankara, 2005.

[2] Türkiye Petrolleri Anonim Ortaklığı A.Ş., "Ham Petrol ve Doğal Gaz Sektör Raporu” Ankara, 2016.

[3] British Petroleum, “BP Energy Outlook 2035” 2015.

[4] M.A. Çukurçayır and H. Sağır "Enerji Sorunu, Çevre ve Alternatif Enerji Kaynakları" Selçuk Üniversitesi Sosyal Bilimler Enstitüsü Dergisi, vol. 20, pp. 257-258, 2008.

[5] T.T.Chow, W.He, J.Ji, "Hybrid photovoltaic thermosyphon water heating system for residental application", Solar Energy, Volume 80, Issue 3, 2006, 298 $-306$.

[6] T.T.Chow, W.He, J.Ji, "An experimental study of façade - integrated photovoltaic water heating system", Applied Thermal Engineering, Volume 27, Issue 1, 2007, $37-45$.

[7] M.N.A.Hawlader, S.K.Chou, M.Z.Ullah, "The performance of a solar assisted heat pump water heating system", Applied Thermal Engineering, Volume 21, Issue 10, 2001, 1049 - 1065.

[8] A. Altıntaş, M.N. Yıldız and İ. Kızılkaya, "İndüksiyon Isıtma Prensibi ile Çalışan Mikrokontrol Denetimli Bir Sıvı Isıtıcısı Tasarımı" Dumlupınar Üniversitesi Fen Bilimleri Enstitüsü Dergisi, vol. 29, pp. 45-52, 2012.

[9] Z. Yuan, C. Li, C. Ma, X. Ren, Z. Zhang, Z. Ren, "Effect of static magnetic heat treatment on microstructures and mechanical properties of DZ483 alloy" Journal of Alloys and Compounds 631 (2015) 86 - 89.

[10] R.Teyber, P.V. Trevizoli, T.V. Christiaanse, P. Govindappa, I. Niknia, A. Rowe, "Permament magnet design for magnetic heat pumps using total cost minimization" Journal of Magnetism and Magnetic Materials, 442, 2017, 87 - 96.

[11] S. Jacobs, J. Auringer, A. Boeder, J. Chell, L, Komorowski, J. Leonard, S. Russek, C. Zimm, "The performance of a large-scale rotary magnetic refrigerator" International Journal of Refrigeration 37 (2014) 84 - 91.

[12] D. Eriksen, K. Engelbrecht, C.R.H. Bahl, R. Bjork, K.K. Nielsen, A.R. Insinga, N. Pryds, "Design and experimental tests of a rotary active magnetic regenarator prototype" International Journal of Refrigeration 58 (2015) $14-21$

[13] C.R.H. Bahl, K. Engelbrecht, R. Bjork, D. Eriksen, A. Smith, K.K. Nielsen, N. Pryds, "Design concepts for a 
continuously rotating active magnetic regenerator" International Journal of Refrigeration 34 (2011), $1792-$ 1796.
[14] J.P.Holman, "Experimental Methods for Engineers", New York. McGraw Hill, 1994. 